\title{
Characterization of milk protein concentrate solubility using focused beam reflectance measurement
}

\author{
Yuan Fang, Cordelia Selomulya, Xiao Dong Chen* \\ Department of Chemical Engineering, Monash University, Clayton Campus, Victoria, Australia
}

\author{
Received 11 May 2009 - Revised 5 November 2009 - Accepted 9 November 2009 \\ Published online 19 January 2010
}

\begin{abstract}
Milk protein concentrate (MPC) is a newly developed dairy powder with high protein content (40-90 wt\%). MPC is known to have relatively poor dissolution properties, rendering traditional testing methods ineffective for characterizing their functionality. To date, various techniques have been used to quantitatively measure the properties of MPC. Mostly, they are conducted offline with considerable sample preparation that influences the reproducibility of the measurement. Here, a methodology to characterize the solubility of MPC using Focused Beam Reflectance Measurement (FBRM) is presented. FBRM provides the ability to monitor in situ the changes in chord length with time over a wide range of suspension concentrations, which directly reflects the solubility of MPC in this case. Faster rate of the chord length reduction implies a better solubility, as more particles break down and dissolve in solution. In this study, the effect of water temperature was investigated for MPC powders. A characteristic dissolution profile for different MPC powders was subsequently established.
\end{abstract}

milk protein concentrate / dissolution / solubility / particle size / FBRM

摘要 - 用聚焦光束反射测量方法 (FBRM) 表征牛乳浓缩蛋白 (MPC) 的溶解度。蛋白浓 缩物 (MPC) 是一种高蛋白质含量 (40-90 wt \%) 的新型乳粉。众所周知, MPC 溶解性相 对较差, 用传统的测试方法无法表征其功能特性。迄今为止, 有很多技术被用来定量测试 MPC 的特性。这些技术大多需要离线制备大批量的样品, 从而影响了测量的可重复性。本研 究用聚焦光束反射测量法 (FBRM) 表征了 MPC 的溶解度。FBRM 能够在一个较宽的悬浮液浓 度 范围内原位监测弦长的变化, 直接反映出 $\mathrm{MPC}$ 溶解度随时间的变化。随着越来越多 的粒子破裂溶解到溶液中, 更快的弦长减幅意味着溶解性越好。此外, 还研究了水温对 MPC 的影响, 并建立了不同 MPC 的溶解特性模型。

\section{浓缩蛋白 / 溶解 / 溶解度 / 粒度 / FBRM}

Résumé - Caractérisation de la solubilité de concentrés de protéines laitières par la technique FBRM. Le concentré de protéines totales de lait (CPT) est une poudre laitière nouvellement développée ayant une teneur élevée en protéine (40-90\%p). Ce produit est connu pour avoir des propriétés de dissolution relativement faibles, rendant les méthodes de mesure traditionnelles inefficaces pour caractériser ses fonctionnalités. À ce jour, différentes techniques ont été utilisées pour mesurer quantitativement les propriétés des CPT. Elles sont majoritairement effectuées hors ligne avec une longue préparation des échantillons qui influence la reproductibilité de la mesure.

*Corresponding author (通讯作者): dong.chen@eng.monash.edu.au 
Une méthode utilisant la technique FBRM pour caractériser la solubilité des CPT est présentée. Cette méthode de mesure de la réflectance d'un faisceau focalisé de lumière permet de suivre in situ les changements de longueur de corde au cours du temps sur une large gamme de concentrations de suspensions qui renvoient directement à la solubilité du CPT dans ce cas. Une vitesse plus rapide de réduction de la longueur de corde signifie une meilleure solubilité puisque plus de particules se cassent et se dissolvent en solution. Dans cette étude, l'effet de la température de l'eau a été étudié sur les poudres de CPT. Un profil de dissolution caractéristique de différentes poudres de CPT a été établi par la suite.

concentré de protéines totales de lait / dissolution / solubilité / taille de particules / FBRM

\section{INTRODUCTION}

Milk protein concentrate (MPC) is a new generation of dairy products, which contains $40-90 \%$ protein in total solid $[11,15]$. The protein content of MPC powder is usually specified as part of its name, for example, MPC 80 and MPC 85 consist of $80 \%$ and $85 \%$ protein contents, respectively $[3,11]$. They are produced by subjecting the skim milk through ultra- and diafiltration prior to drying in order to remove lactose and minerals $[4,11]$. MPC has a wide range of applications as ingredients in the food and beverage industry for cheese and yoghurt manufacture, confectionery, energy drink, and coffee. In the manufacture of cheese, the protein content of milk can be increased by adding MPC powder that improves the efficiency and consistency of the resulting cheese product [3]. However, their uses are somewhat restricted due to the varying solubility of the different MPC powders [4], especially under cold water [3].

It is well known that MPC powder has a very poor dissolution property. This challenging issue has brought about various studies to quantify the functional properties of MPC powders [1, 7, 11, 19]. The functionality of MPC varies according to their different composition, heating history, and storage duration, with MPC solubility reported to decrease with storage time and storage temperature $[1,20]$. A possible explanation for this particular phenomenon is that the proteins on the surface of MPC powder form cross-linked networks with neighbouring proteins (on adjacent powder) during storage. This cross-linked network could act as a barrier for water to penetrate, thus inhibiting the rehydration of MPC particles [1]. However, it is noted that the increasing number of cross-links adversely affects the solubility of the powder only after a certain threshold limit of the crosslink [1]. Previous studies also have indicated no clear correlation between the protein content and the functionality of MPC [4].

In recent years, more studies have been conducted to characterize the MPC dissolution properties. One such study determined the solubility of MPC using a centrifugation technique, by separating the MPC into two fractions: the soluble protein in the supernatant and the insoluble protein in the sediment [11]. In this study, aggregated proteins may be classified as 'soluble' (in the supernatant) or as 'insoluble' (in the sediment) depending on the experimental conditions such as different centrifugation speed. As such, it was concluded that the term 'solubility' should only be considered as a relative measure and was specific for a fixed set of experimental conditions [11]. In another study, a turbidity sensor was employed to measure the rehydration property of protein-rich dairy powders [8]. With the assistance of other techniques (such as static light scattering microscopy), turbidity was used as a measure to differentiate the different powder rehydration phases 


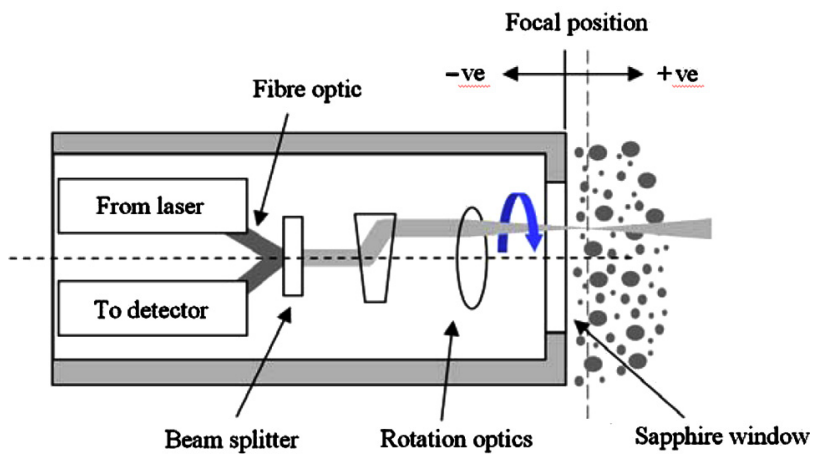

Figure 1. Schematic of the FBRM probe.

in building a rehydration profile, from wetting and swelling phase, to the dispersion phase, and finally a homogeneous fluid liquid phase. In some of the studies, the dissolution properties of dairy powders were characterized using Malvern Mastersizer (Malvern Instruments Ltd., Malvern, UK) $[5,7,9,10,18]$. However, this method requires sample preparation such as dilution and is restricted to a very dilute concentration of MPC powders $(<0.1 \%)$. During the analysis process, the measuring solution is pumped from the stirring tank to the sample cell in which the laser light is transmitted through a Fourier lens [18].

Here, the technique of Focused Beam Reflectance Measurement (FBRM) was employed to characterize the solubility of MPC powders. FBRM technique provides in situ monitoring of particle size and the change in particle counts (PC) [12-14, 16, $17,22]$, in a relatively robust manner without the need for offline sampling. This unique property enables FBRM to be widely applied in both industrial and laboratory processes, such as crystallization [14] and fluidized bed granulation [13]. The hardware configuration of this device primarily consists of a laser probe and a stirrer to keep the sample well mixed as depicted in Figure 1. Inside the probe, a $780 \mathrm{~nm}$ laser beam is directed through a lens rotating at a speed of $4500 \mathrm{rpm}$ [12]. The laser beam is focused onto a point near the sapphire window of the probe. The size of the focused beam is $\sim 0.7 \mu \mathrm{m} \times 2 \mu \mathrm{m}$ [12]. When the rotating beam comes across an entity in the measuring solution, part of it is reflected back and picked up by the detector. As the tangential velocity of the beam is known, the detector can measure the duration of the reflected light proportional to the width of the particle. In this case, the measured distance across the particle is known as the chord length calculated by equation (1). Typically, thousands of chord length are measured per second, with the numbers of counts dependent on the concentration of solids present in the suspension [2]. However, the results from FBRM can be related to both particle diameter and shape [2]. In this case, MPC particles are assumed to be spherical particles. As the powders start to dissolve, they break up into smaller-sized agglomerates, subsequently into primary particles, and eventually releasing the materials into solution. This dynamic change in size over the whole sample will be reflected by the decrease in the average chord length across the whole population of the powder. Therefore, by monitoring the change in average chord length of the sample with 
time using FBRM, the solubility profile of MPC can be quantitatively represented and reported as chord length in this study:

$$
\begin{aligned}
\text { Chord length }= & \text { beam velocity } \\
& \times \text { measuring duration } .
\end{aligned}
$$

In the dairy industry, powder dissolution is considered as the key determinant of the overall reconstitution quality. The aim of this study is to investigate the suitability of FBRM as a tool to characterize MPC solubility, so that a protocol for quantifying dissolution of MPC can be proposed and the dissolution profile of MPC established. In comparison to other light scattering techniques to measure particle size (i.e. Malvern Mastersizer), FBRM can be used directly in situ without the need of further dilution of samples. The method for monitoring the change in MPC chord length with time using FBRM was outlined in the methods section. The suitability of using FBRM as a tool to quantify solubility was first assessed by comparing the results with those obtained from standard insolubility tests. The effects of different parameters such as stirring rate and initial powder concentration were also investigated to minimize inconsistency due to testing conditions. The particle size population counts were investigated, which can provide further information regarding different particle dissolution mechanisms.

Using the FBRM data, a dissolutiontemperature profile is generated for each MPC powder. This study is the first step to establish a dynamic dissolution model for dissolution kinetics of MPC in particular. The future model is expected to provide greater insights into MPC powder dissolution behaviour under specific conditions.

\section{MATERIALS AND METHODS}

\subsection{Materials}

Six types of industrial spray-dried MPC powders with different protein contents, heating and storage history were obtained from a local dairy factory. They were categorized as powders $\mathrm{A}, \mathrm{B}, \mathrm{C}, \mathrm{D}, \mathrm{E}$, and $\mathrm{F}$, respectively. (Further details of these powders are not mentioned here due to reasons of confidentiality.)

\subsection{Experimental setup and procedure}

Each experiment was carried out in a $600 \mathrm{~mL}$ vessel that was equipped with an overhead stirrer 4-blade impeller of $50 \mathrm{~mm}$ diameter (RW16, IKA WERKE, Germany), rotating at $800 \mathrm{rpm}$. The testing temperature was preset and maintained at $20,30,40,50$, and $60{ }^{\circ} \mathrm{C}$ using a water bath as shown in Figure 2.

For each set of tests, $7.5 \pm 0.01 \mathrm{~g} \mathrm{MPC}$ powder were measured and poured into the beaker with $500 \mathrm{~mL}$ distilled water, preheated up to the testing temperature before commencement of the experiment, to make up a $1.5 \mathrm{wt} \%$ solution. The stirrer was adjusted to a stirring rate of $800 \mathrm{rpm}$. The data from FBRM was collected using an iC FBRM ${ }^{\mathrm{TM}}$ software (Mettler Toledo), and the data collecting interval was set at $10 \mathrm{~s}$ with the measuring duration of $30 \mathrm{~min}$. After $30 \mathrm{~min}$, the insolubility test was carried out according to the Niro method A 3 a [21] with a slight modification as follows. The resulting solution from FBRM was collected into four centrifuge tubes using a $50 \mathrm{~mL}$ syringe. Each tube was filled with about $50 \mathrm{~mL}$ of mixture sample. The weight of each centrifuge tube before and after filling with sample solution was recorded. The sample solution was then centrifuged for $5 \mathrm{~min}$ at $1000 \mathrm{rpm}$ and the supernatant was discarded. The sediment 

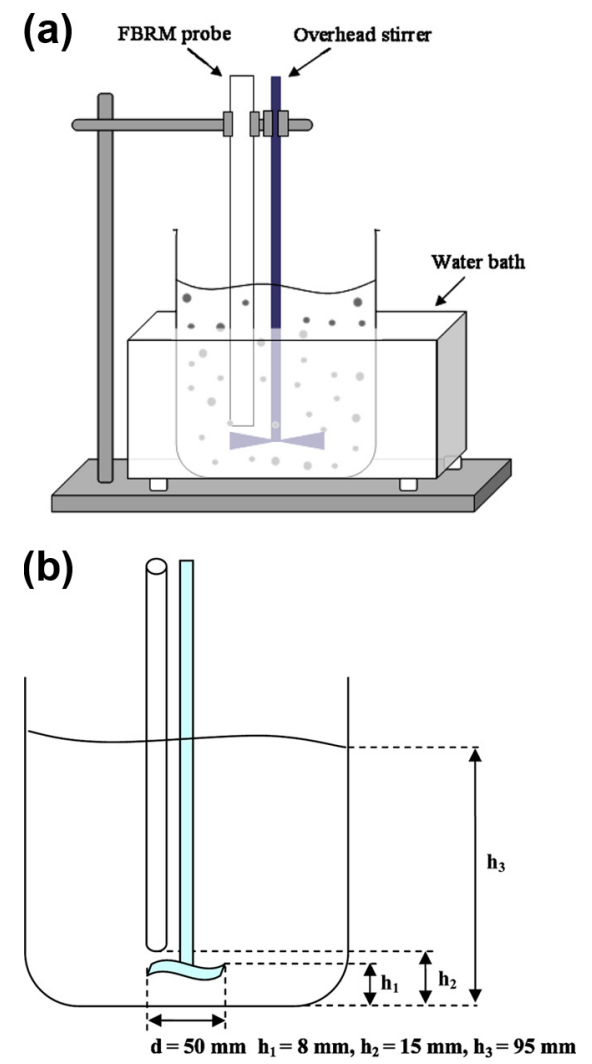

Figure 2. Schematic of the experimental setup. (a) Experimental setup and (b) dimensions of vessel used for the experiment.

remaining at the bottom of the tubes was extracted and dried overnight at $50{ }^{\circ} \mathrm{C}$ in the oven. The sediment amount after drying was recorded. The insolubility index (ISI) of the different MPC powders was calculated using equation (2):

$$
\mathrm{ISI}=\frac{m_{\text {tube }+ \text { sed }}-m_{\text {tube }}}{m_{\text {tube }+ \text { sol }}-m_{\text {tube }}} \times 100 \%
$$

where $m_{\text {tube }}$ is the weight of empty centrifuge tube, $m_{\text {tube+sed }}$ is the weight of tube with sediment after drying, and $m_{\text {tube }+ \text { sol }}$ is the weight of centrifuge tube with solution before centrifugation.

One needs to note that given long enough time, MPC would dissolve completely in most cases (Bandhari, personal communication, 2009). Hence, the ISI actually characterizes a dynamic behaviour. The consumers who use the powders are often interested in 'shorter' time behaviour.

\subsection{Relative particle counts and initial particle size}

In this study, the PCs of different powders were recorded. FBRM could provide data such as particle population information based on particle size ranges from 1 to $1000 \mu \mathrm{m}$. The software by default divided the particle population into five groups, namely those with a particle size $<10 \mu \mathrm{m}$, between 10 and $50 \mu \mathrm{m}, 50$ and $150 \mu \mathrm{m}$, 150 and $300 \mu \mathrm{m}$, and 300 and $1000 \mu \mathrm{m}$, respectively. In this study, the general dissolution behaviour of the powders investigated with particle populations was classified into three categories: fine particles $(1-10 \mu \mathrm{m})$, median particles $(10-150 \mu \mathrm{m})$, and the big/ agglomerate particles $(150-300 \mu \mathrm{m})$. It is noted that for the set of powders used in this paper, no PC within $300-1000 \mu \mathrm{m}$ was detected in all the experiments.

The experimental procedure described in Section 2.2 was also carried out at $0{ }^{\circ} \mathrm{C}$. The last $5 \mathrm{~min}$ of readout from the FBRM was averaged and defined as the initial particle size in suspension of a particular powder (A-F). It is expected that the particle size will not vary at such a low temperature. This will be utilized as the baseline for the analysis of the dissolution kinetics for a particular powder at different testing conditions. As such, the $\mathrm{PC}$ at this early stage of dissolution (i.e. $0{ }^{\circ} \mathrm{C}, 1 \mathrm{~min}$ from dissolution commencement) will be the reference PC for subsequent dissolution analysis. 
For the dissolution analysis of each type of powder, the relative particle count (RPC) was calculated using equation (3):

$$
\mathrm{RPC}_{i, \mathrm{tmp}}(t)=\frac{\mathrm{PC}_{i, \mathrm{tmp}}(t)}{\mathrm{PC}_{i, 0}{ }^{\circ} \mathrm{C}(1 \mathrm{~min})}
$$

where $\mathrm{RPC}_{i, \mathrm{tmp}}(t)$ is the RPC of powder $i$ at certain testing temperature tmp at time $t$, $\mathrm{PC}_{i, \mathrm{tmp}}(t)$ is the actual PC of powder $i$ at certain testing temperature tmp at time $t$, and $\mathrm{PC}_{i, 0}{ }^{\circ} \mathrm{C}(1 \mathrm{~min})$ is the $\mathrm{PC}$ for powder dissolved at $0{ }^{\circ} \mathrm{C}$ solution after $1 \mathrm{~min}$.

\section{RESULTS AND DISCUSSION}

\subsection{Defining solubility for MPC}

Figure 3 shows the changes in chord length as represented by chord length measured by FBRM against time for powders A-F. Each curve represents data plotted at a specific testing temperature.

As solubility is a relative measure that varies according to different testing conditions [11], it is necessary to define a physical quantity of measure for the solubility of MPC powders, considering the dynamic nature of this solubility as mentioned earlier. Using FBRM, the mean chord length of the particles in suspension was used to quantify powder solubility. During the dissolution process, agglomerated MPC particles would gradually break up into smaller particles $[6,19]$, which was shown by the decrease in chord length from the FBRM readout. A smaller chord length measured would imply a lesser amount of undissolved particles in the suspension. If the suspension still contained undissolved particles, the standard insolubility test (Niro method A 3 a) should exhibit the presence of sedimentation after centrifugation. Therefore, the chord length from FBRM should be directly related to the amount of sediment (insolubility test) for a particular powder, giving rise to the same relationship trend under different testing conditions as observed in Figure 4.

Firstly, we compared the data from FBRM to the insolubility test obtained for each powder. This was done by averaging the chord length from FBRM (between 100 and $1800 \mathrm{~s}$, and will be explained in detail in the next section) for each temperature. Results from both tests exhibit similar trends for the solubility of the powder at different temperatures, thus verifying that FBRM can be adopted as a technique to assess the solubility of MPC powders.

An assumption which is taken usually is that after centrifuging the sample, the particles remaining in the supernatant were considered to be dissolved. To quantify this 'threshold' level of chord length (below which the powders are considered dissolved), the following experiment was conducted. After centrifugation of the sample, the supernatant was measured by FBRM for $5 \mathrm{~min}$. The measurement was duplicated, and the FBRM results for all powders are as shown in Figure 5. The results indicated that the chord length (of the supernatant) for all the measurements was $\sim 100 \mu \mathrm{m}$, regardless of the particle size of the initial solution. This is an important information. Therefore, any particle with particle size $<100 \mu \mathrm{m}$ will be considered to be 'dissolved' in this study for practical purpose.

In the case of powder B, the chord length of the original solution was $75 \mu \mathrm{m}$ before centrifugation, but increased to $96 \mu \mathrm{m}$ after centrifugation. A possible explanation is that the small particles might have come into contact and aggregated onto each other and form larger particles under high shearing rate of centrifugation. These larger particles (size $>96 \mu \mathrm{m}$ ) were removed along with the sediments, while the smaller particles $(<96 \mu \mathrm{m})$ remained in the solution. This resulted in an increasing chord length of the supernatant after centrifugation. 

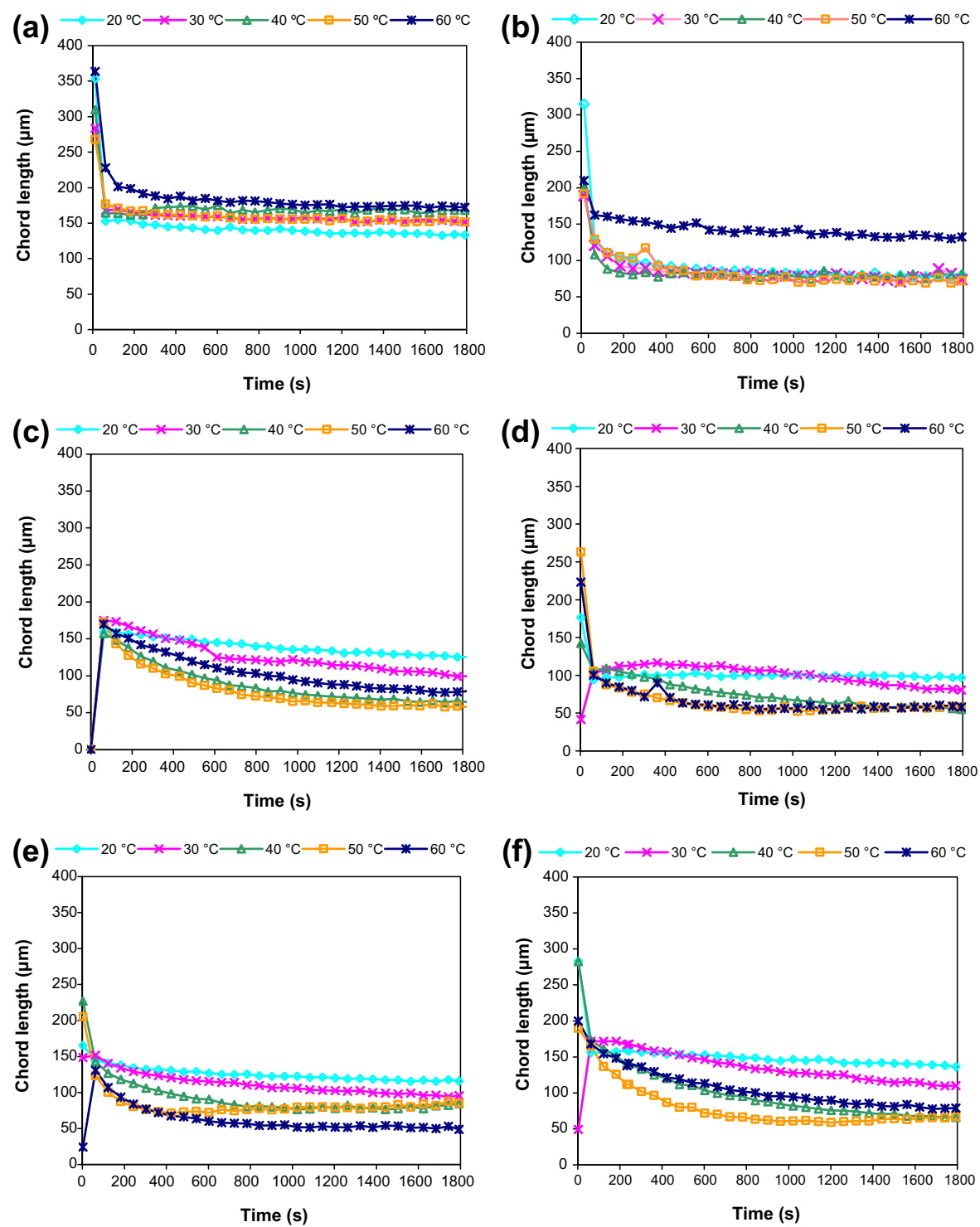

Figure 3. Results of powders A-F obtained from FBRM: (a) powder A; (b) powder B; (c) powder C; (d) powder D; (e) powder E; and (f) powder F.

\subsection{Establishing the dissolution profiles of MPC}

From the FBRM data shown in Figure 3, it can be seen that at the beginning of each run, there was a sudden and sharp increase in the chord length, after which it decreased and reached a plateau. A probable cause was when the powder was poured onto the water surface, the powder first started 
(a)
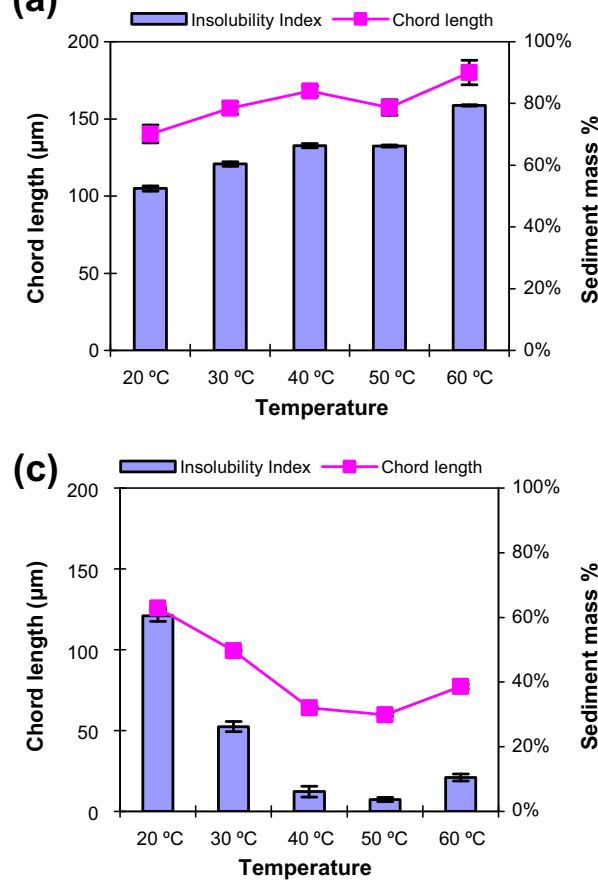

(e)

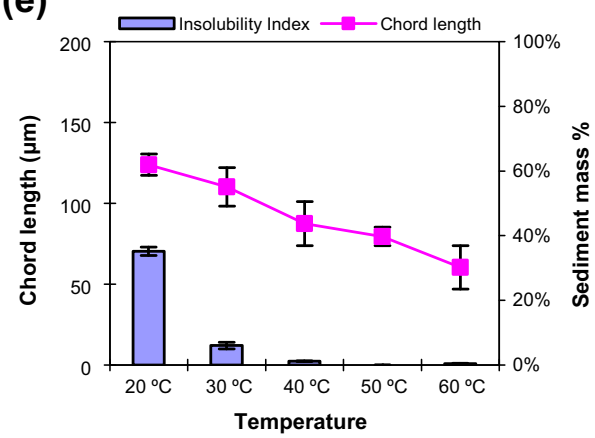

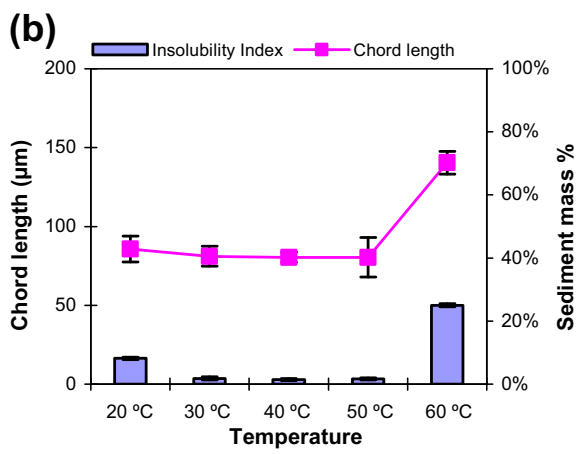

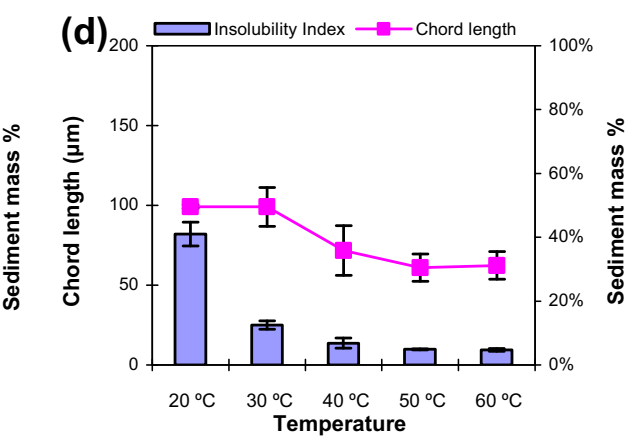

(f)

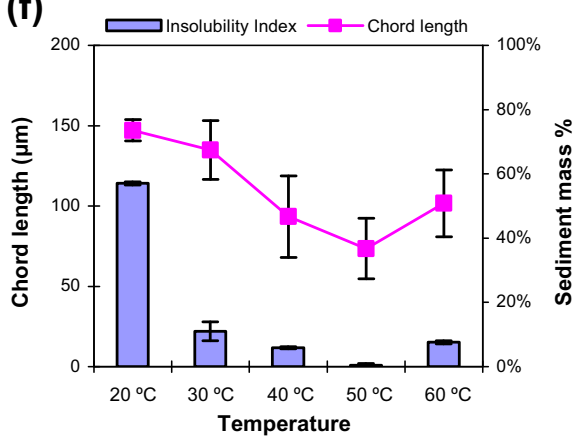

Figure 4. Powder A-F chord length/insolubility against temperature: (a) powder A; (b) powder B; (c) powder C; (d) powder D; (e) powder E; and (f) powder F.

to sink into the water causing the PC to increase dramatically until all the powders had fully immersed. Thus, the FBRM reading showed large particle size with low PC initially, while the chord length increased sharply from 0 to the measured particle size. In this case, in order to have a reproducible starting point for monitoring powder dissolution, the FBRM measured particle size at $0{ }^{\circ} \mathrm{C}$ was defined as the original size of the specific powder and used in Section 3.4 as the initial particle size for dissolution kinetic analysis.

From Figure 3, it can be observed that the dissolution behaviour of various powders was very different due to the fact 


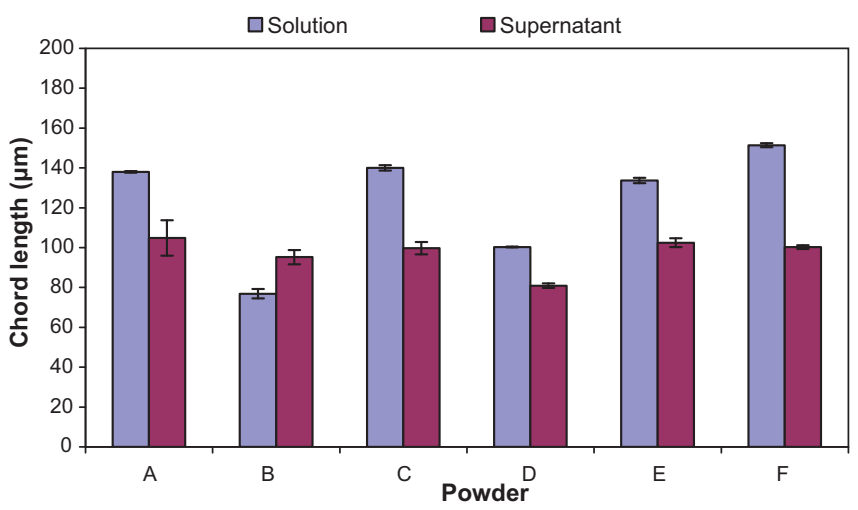

Figure 5. Chord length of both original solution and supernatant of powders $\mathrm{A}-\mathrm{F}$ at $20{ }^{\circ} \mathrm{C}$.

that the powders had been subjected to different production and storage conditions, in addition to the different protein contents. For powder A, the chord length increased with increasing testing temperatures, implying that the solubility of powder A was worse at increasing testing temperature. Powder A had the best solubility at $20{ }^{\circ} \mathrm{C}$ and was least soluble at $60^{\circ} \mathrm{C}$. For powder $\mathrm{B}$, the chord length at $20-50{ }^{\circ} \mathrm{C}$ was similar, but then increased sharply at $60{ }^{\circ} \mathrm{C}$, implying that powder $\mathrm{B}$ was more soluble between 20 and $50{ }^{\circ} \mathrm{C}$, and less soluble at $60{ }^{\circ} \mathrm{C}$. For powders $\mathrm{C}, \mathrm{D}$, and $\mathrm{F}$, similar dissolution trends were observed, with all of them showing better solubility at $50{ }^{\circ} \mathrm{C}$ than at any other temperature. For powder E, the chord length decreased with increasing temperature. This indicates that its solubility increased with temperature ranging from 20 to $60{ }^{\circ} \mathrm{C}$. Generally, it was noted that the solubility decreased (indicated by chord length increase) at higher temperature $\left(>50^{\circ} \mathrm{C}\right)$ for most of the powders. These results also indicate that the solubility of MPC powder was strongly affected by the testing condition (e.g. the temperature), which is in agreement with the findings of Mimouni et al. [19]. This dependence on temperature could be due to the further denaturation and the greater extent of aggregation of proteins at higher temperatures, causing an increase in particle size, and hence poorer solubility. In addition, it can be seen from Figure 3 that for all powders at each testing temperature, the chord length exhibited the most dynamic changes in the first $200 \mathrm{~s}$. This indicates that the majority of MPC powders' dissolution activities occurred during this period.

These results highlight the usefulness of FBRM to characterize the dissolution behaviour of different MPC powders in situ and in a reproducible manner. For the other testing condition studied (e.g. stirring speed and solid concentration), refer to Appendix (Sect. 5).

\subsection{Particle size population analysis}

During the dissolution of a powder, two processes are known to occur simultaneously: the breaking up of agglomerates into primary particles and the dissolution of primary particles into solution [19]. Intuitively, the solubility of a certain powder is directly related to how well the powder breaks down into its constituent components. It is therefore important to understand the dynamics of different particle size population during the course of dissolution process. 
With different particle sizes, the three particle populations are expected to show different behaviour during dissolution. Therefore, it is expected that the number of particle sizes between 150 and $300 \mu \mathrm{m}$ (large particle population) should decrease with time, whereas the number of particle sizes between 1 and $10 \mu \mathrm{m}$ (fine particle population) may actually increase with time. The medium particle population size could vary due to the influx and efflux of particles between the other two populations.

Comparison of the RPC for fine particles and large particles clearly shows different dissolution behaviour as demonstrated in Figure 6. Taking powder A as an example of a poorly soluble powder, the fine particle population counts for powder A increased only slightly from 0 to 1 in the first $200 \mathrm{~s}$ and remained relatively constant thereafter for all testing temperatures. As for the large particle population counts, the RPC decreased from 1.2 to 1 at $60{ }^{\circ} \mathrm{C}$ with similar trends observed for other temperatures. This indicated that for powder $\mathrm{A}$, both the fine and large particle population counts did not change significantly within the testing period, implying that the particles hardly break up from the agglomerates to form into smaller particles $(<10 \mu \mathrm{m})$. This could be due to possible predenaturation or drying (concentrate the small elements within each particle of MPC) during processing where elements contact tightly, making them extremely hard to break down. Therefore, powder A's dissolution rate is attributed to the limitation of the rate of de-agglomeration.

This difference in solubility and RPC results between the different size populations can be further emphasized by comparing with powder $\mathrm{F}$, an example of a powder with good solubility. Figure 6 shows the RPC of fine and big particles for both powders $\mathrm{A}$ and $\mathrm{F}$, and it is clear significant differences were observed.

Dissolution of the powder can be clearly seen in the change of RPC with dissolution time as the fine particle population count increases significantly, whereas the large particle population count decreases substantially (to zero in some cases). The dissolution trends between different testing temperatures could be clearly observed for powder F. The RPC of powder F fine particles shows significant increase till the end of dissolution, with the rate of increase dependent on the testing temperature (from 1.7 at $20{ }^{\circ} \mathrm{C}$ to 13.6 at $50{ }^{\circ} \mathrm{C}$, slightly decreasing to 13.3 at $60{ }^{\circ} \mathrm{C}$, all recorded at $1800 \mathrm{~s}$ ). As for the RPC of large particle population, the rate of decrease was also dependent on the temperature with increasing rate from 20 to $50{ }^{\circ} \mathrm{C}$ and then decreasing at $60{ }^{\circ} \mathrm{C}$. This indicates that at a higher dissolution temperature (i.e. $50{ }^{\circ} \mathrm{C}$ ), powder $\mathrm{F}$ readily de-agglomerates into primary particles, consequently, reducing the dissolution time.

The results are also verified by the images taken using SEM and light microscopy as shown in Figures 7 and 8. From SEM images, it is clear that the dry particles of powder A appear to be highly agglomerated, whereas the dry particles of powder $\mathrm{F}$ appeared to be smoother and less agglomerated. From light microscopy images, powder A particles still remained in agglomerated form even after dissolution at $20^{\circ} \mathrm{C}$, whereas the particles of powder $\mathrm{F}$ appeared as fine particles under the same condition.

Taken together, these results show that the population analysis with FBRM can be used to characterize the dissolution dynamics and solubility of different powder types. In this instance, it successfully monitored the dissolution dynamics of specific powders and also distinguished between powders with good and poor solubility.

Additional information can also be obtained from population analysis. As mentioned earlier, there were two phenomena observed during dissolution. One was the de-agglomeration of big particles shown by the decrease of RPC for big particles. The other was the breaking down into primary particles which is shown by the increase of RPC of fine particles. However, at the early 
(a)
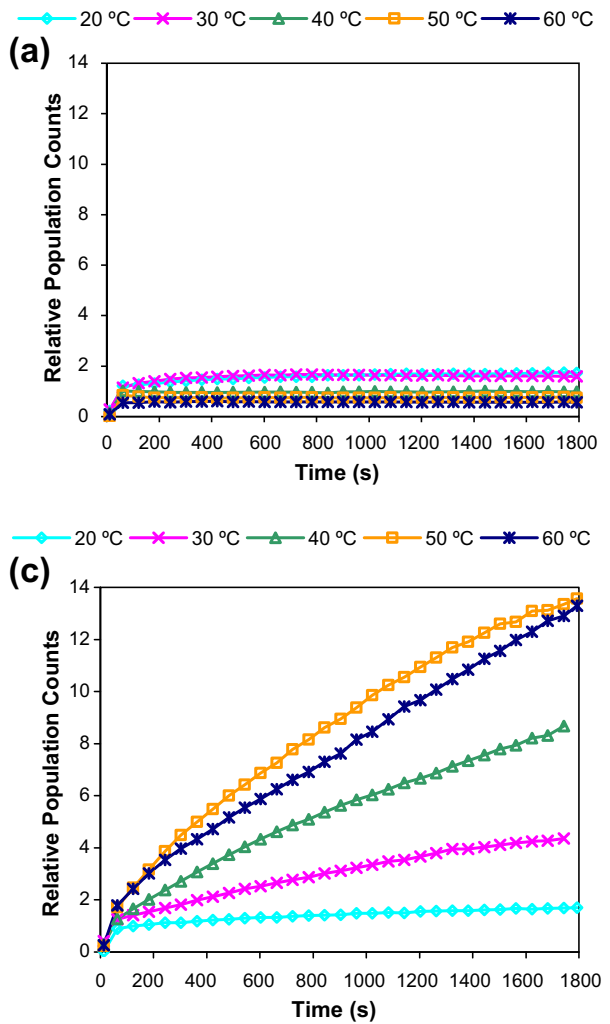

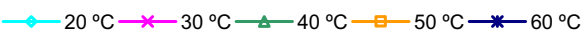

(b)

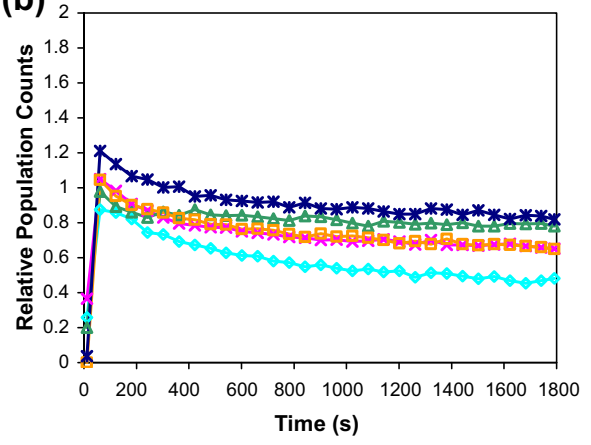

$\longrightarrow 20^{\circ} \mathrm{C} \rightarrow-30^{\circ} \mathrm{C} \triangle 40^{\circ} \mathrm{C} \square-50^{\circ} \mathrm{C} \rightarrow 60^{\circ} \mathrm{C}$

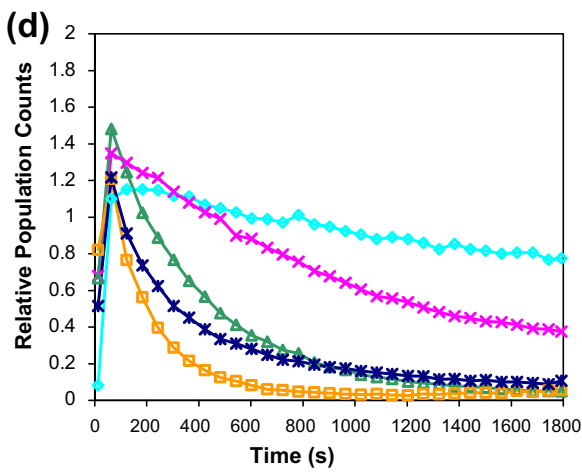

Figure 6. Relative population counts for fine/big particles of powders A and F: (a) powder A fine PC; (b) powder A large PC; (c) powder F fine PC; and (d) powder F large PC.

period of each test, it was noted that there was a significant rise in the RPC for the large particle population. The RPC values in this case were $>1$ (i.e. powder $\mathrm{A}$, increase from 0 to 1.2 by 1 min at $60{ }^{\circ} \mathrm{C}$ ), which meant a greater number of big particles as compared to the initial number. This was possibly caused by the collision of particles during stirring. This sudden increase was also observed in the RPC for the fine particle population (i.e. powder A, increase from 0 to 0.5 by $1 \mathrm{~min}$ at $60{ }^{\circ} \mathrm{C}$ ). Taken together, looking at the chord length plot that takes into account all the populations of particles, it can be deduced that both increases of big and fine particles at the early period of each experiment indicate the competition of the two processes, agglomeration and breaking up, for the powder particles. On the one hand, collision due to stirring acts to increase big particles by 'combining' smaller particles, while on the other hand, the breaking up process tries to increase the fine particle population by breaking up larger particles into smaller ones. These effects last only for a very short period of time until the particles start to disperse into the water. This effect is more prominent in the large particle population, and subsequent changes in the numbers of big particles will therefore significantly affect the chord length. As such, the collision of large particles can be considered the dominant 


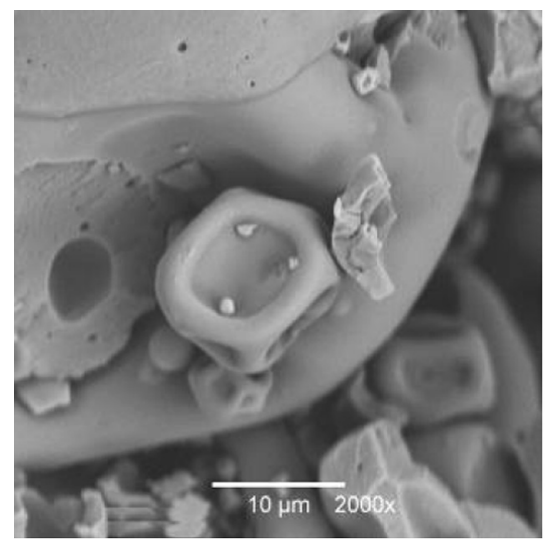

(a) Powder A

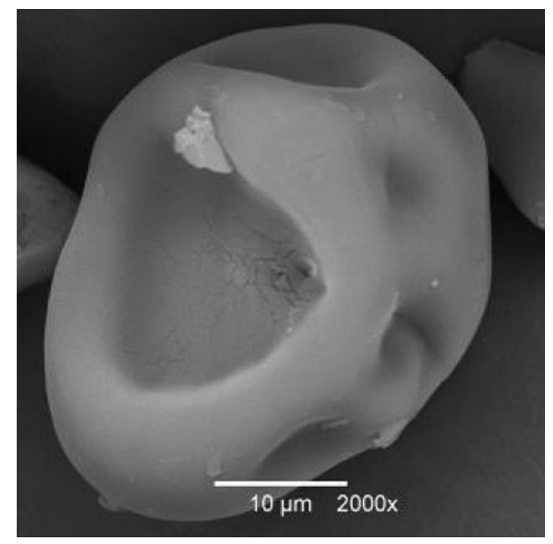

(b) Powder F

Figure 7. SEM image of powders $\mathrm{A}$ and $\mathrm{F}$.

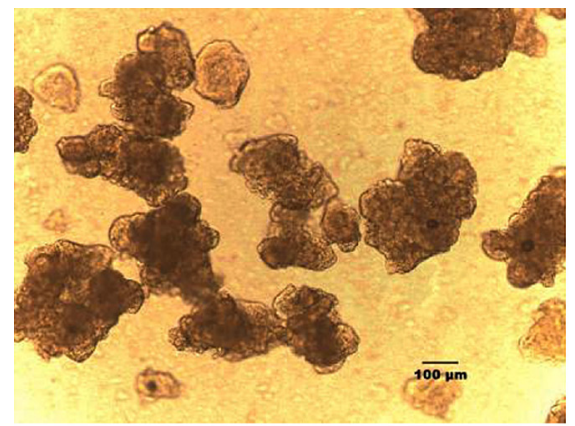

(a) Powder A after dissolution $\left(20^{\circ} \mathrm{C}\right)$

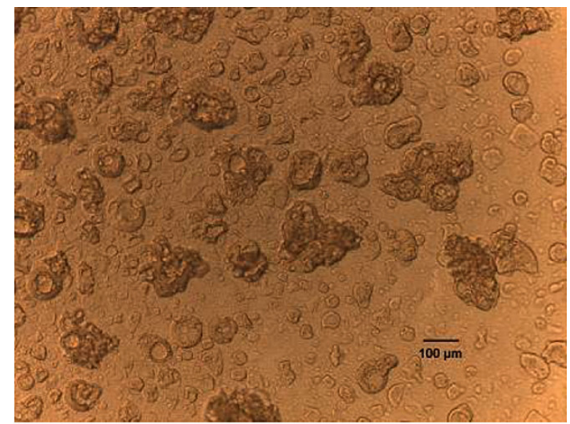

(b) Powder $\mathrm{F}$ after dissolution $\left(20^{\circ} \mathrm{C}\right)$

Figure 8. Light microscopy results of powders A and $\mathrm{F}$ dissolved at $20^{\circ} \mathrm{C}$.

process at the beginning of dissolution and reflected by the sharp increase in chord length at the start of each experiment.

\subsection{Characterization of MPC dissolution parameters with FBRM}

Using the dissolution-temperature profile for various powders formulated by the FBRM analysis, a better understanding of the dynamic behaviour of these powders can be obtained. One way to achieve this is by data fitting the experimental data obtained to investigate any correlation between data parameters and process conditions. The changes in particle size from the original particle size to steady state under different temperatures were fitted with logarithmic plots that gave the best fit as shown in Figure 9. From the fit, the following parameters can be obtained: 
- The initial dissolution rate indicates how fast the chord length drops from the original particle size until it reaches equilibrium (i.e. the gradient/slope of the fitting curve). The greater the magnitude implies a faster dissolution rate of the powder.

- The lag time is defined as the duration from when the powder is first introduced until the chord length in suspension reaches the original particle size (i.e. defined as the starting point to monitor powder dissolution). The lag time gives an indication on how fast the powder is being wetted, the degree of compactness and agglomeration that will affect the amount of surface area the powder interacts with the water. The results from Section 3.3 also indicate the cause of lag time, which is possibly due to the collision of particles. The duration required to break up colliding particles is dependent on the property of particles (i.e. hydrophobicity). The shorter the lag time, the easier the agglomerates break up into smaller particles with a greater surface area contact with water surface, and thus a better solubility. This is conversely true for a longer lag time. As such, these properties could provide an indirect relationship between the physical and functional properties.

For a few of the powders (i.e. powders A, $\mathrm{B}$, and $\mathrm{D}$ ), there are several temperature points missing. This is due to the fact that the particle size did not drop below the initial particle size within the testing period.

The normalized slope-temperature profile curve and lag-time-temperature profile curve are plotted as shown in Figure 10. In general, the normalized insolubility testand FBRM results were able to reproduce the 'U'-shaped dissolution profile trend over the testing temperature, with the minimum value shown to be at around $40-50{ }^{\circ} \mathrm{C}$.
This suggests that powders B-F have the best solubility at around $40-50{ }^{\circ} \mathrm{C}$ (powder B at $40{ }^{\circ} \mathrm{C}$ ). However, no slopetemperature profile and lag-time-temperature profile were available for powder A as only one set of temperature-data profiles acquired was applied for this analysis. As for the normalized slope and lag-time profiles, the results generally correlate well with those of the insolubility and FBRM results. As expected, the ' $U$ '-shaped trend was once again observed for powders B-F over the testing temperature, which again indicates the fastest dispersion and dissolution rate to be around $40-50{ }^{\circ} \mathrm{C}$.

This highlights the potential of these various techniques in formulating standard models to characterize the properties of these various powders. In particular, the profiles generated from the initial rate and lag-time data can potentially be applied to reduce the required testing time. As these two parameters are derived from the early stages of the dissolution process (which is when most of the dissolution events occur), the amount of time needed to acquire such data can be considerably reduced. The profiles generated can be used for quick analysis of a certain powder to determine the possible functionality of the powder without the need to conduct a lengthy dissolution test. This could potentially save time, labour cost and equipment usage time.

\section{CONCLUSION}

This study has demonstrated the applicability of FBRM to characterize the solubility of MPC powders. A systematic approach has been taken, which offers a versatile and reproducible manner for quantifying the solubility of MPC powder under different conditions. One advantage of FBRM is that it can handle high solid content suspensions. This method can provide the capacity to quantitatively measure the dissolution 

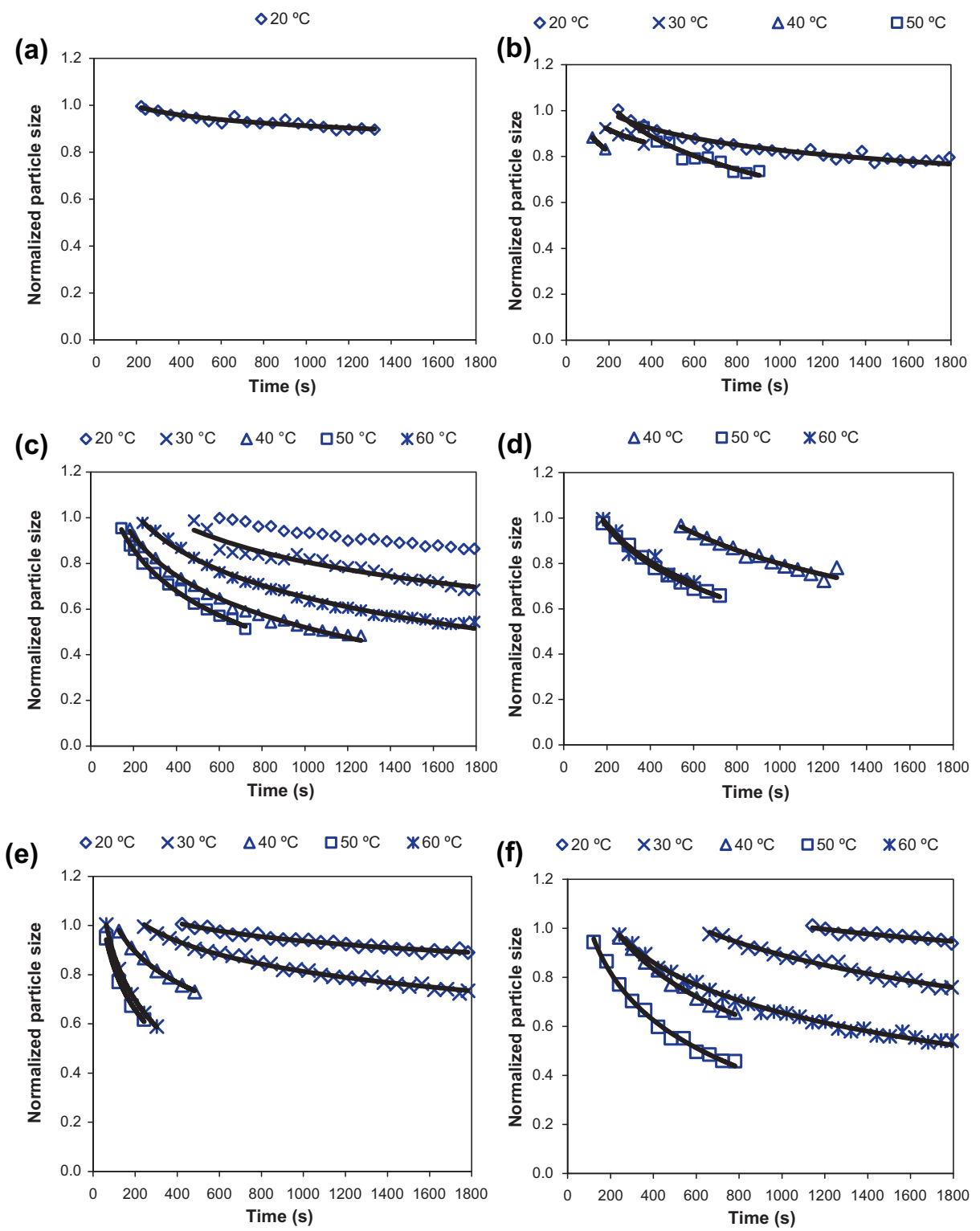

Figure 9. Normalized particle size of powders A-F: (a) powder A; (b) powder B; (c) powder C; (d) powder D; (e) powder E; and (f) powder F.

behaviour for a specific powder under a set of specific conditions. The FBRM results have indicated that solubility of MPC pow- ders is strongly affected by testing water temperature. The most dramatic changes in chord length take place in the first $200 \mathrm{~s}$ 

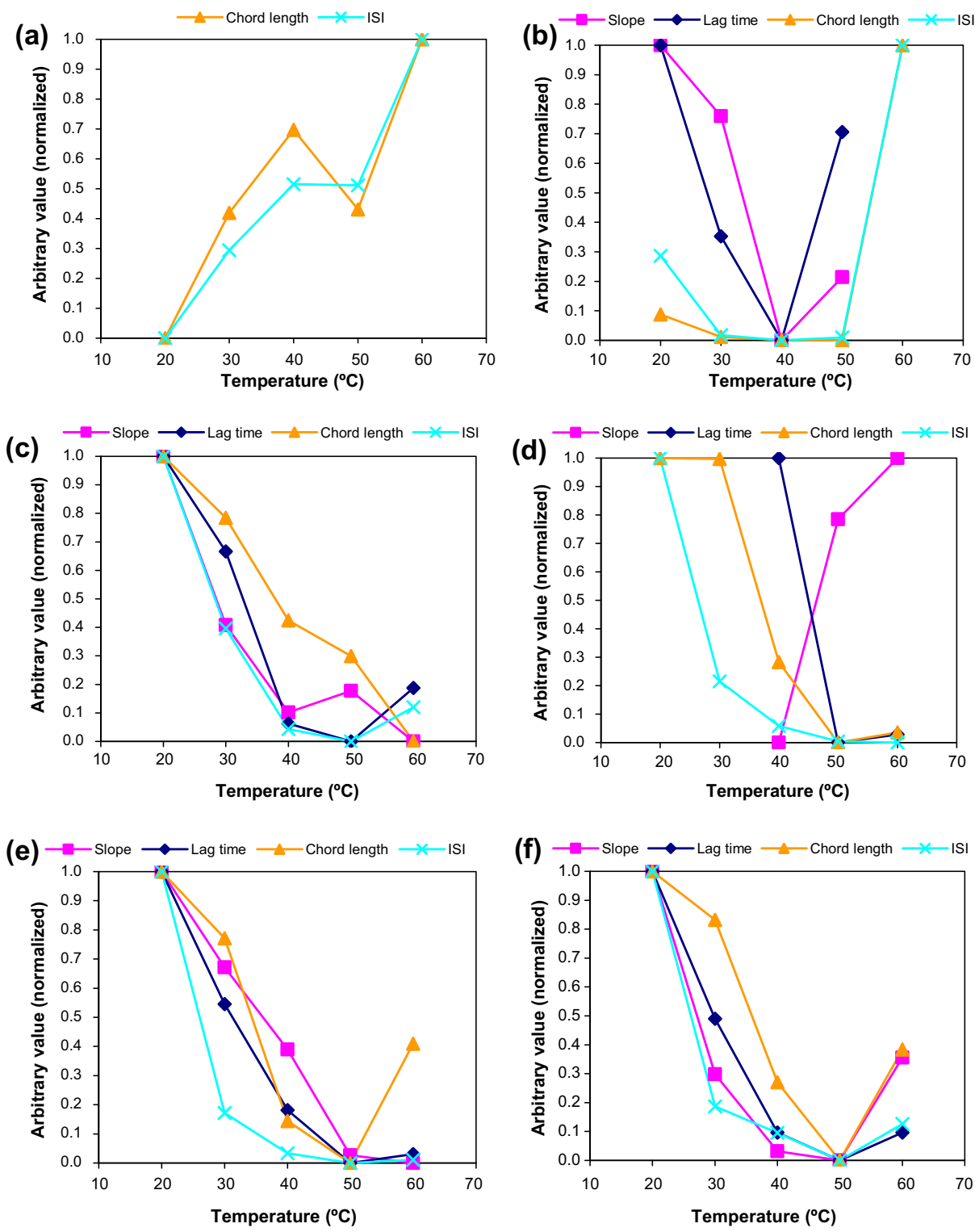

Figure 10. Normalized parameters of powders A-F (ISI, insolubility index): (a) powder A; (b) powder B; (c) powder C; (d) powder D; (e) powder E; and (f) powder F.

of the dissolution test. An analysis based on particle population counts has also been proposed to characterize the dissolution behaviour of different MPC powders.
More significantly, this protocol can potentially be applied within the dairy industry to easily predict the solubility of a powder at any specific temperature from 


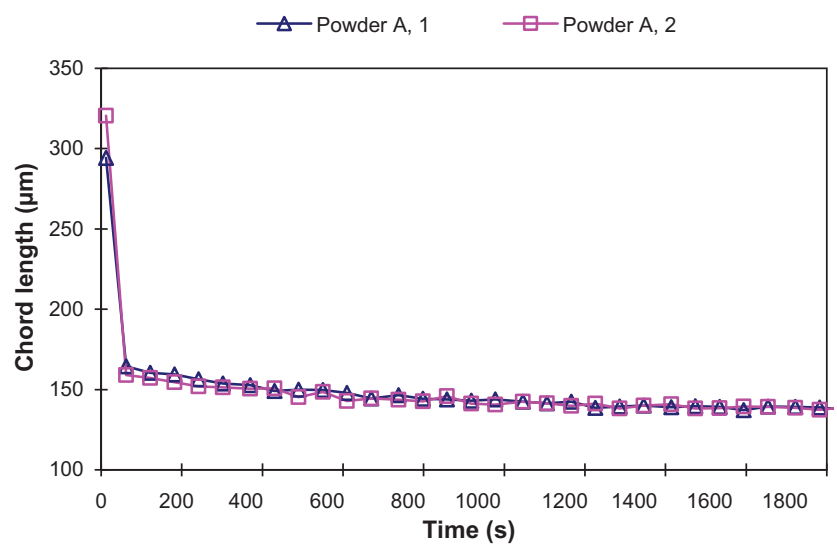

Figure A1. Chord length of powder A at $20{ }^{\circ} \mathrm{C}$ (repeat measurement).

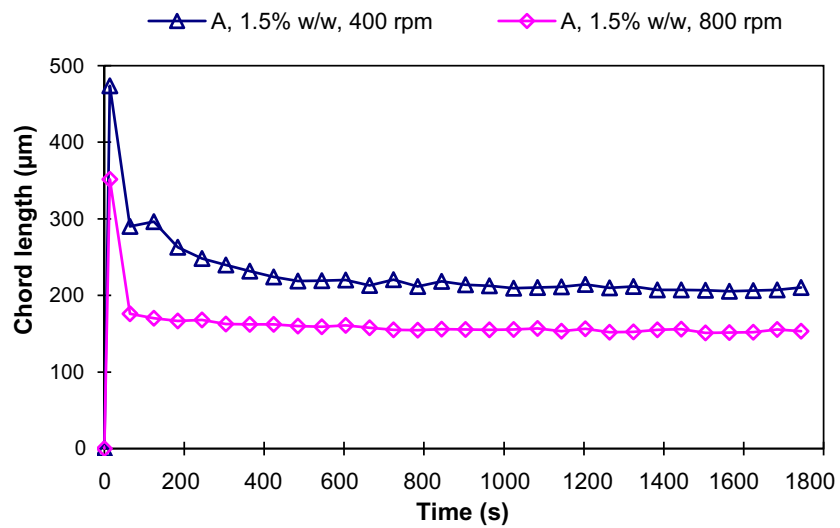

Figure A2. The effect of stirring rate on the chord length of powder A at $50{ }^{\circ} \mathrm{C}$.

its dissolution-temperature profile. The relatively quick analysis for characterizing dairy powders should be beneficial for quality control and for reducing the cost of dairy milk production. The next step (to be reported in future) is to establish an index to define the level of solubility to quantify the extent of the solubility of MPC powder.

\section{APPENDIX}

\subsection{Reproducibility of the solubility measurement of MPC}

The reproducibility of solubility measurement of MPC powders was investigated using FBRM. The measurement was carried out using powder $\mathrm{A}(7.5 \mathrm{wt} \%)$ at $20{ }^{\circ} \mathrm{C}$, 


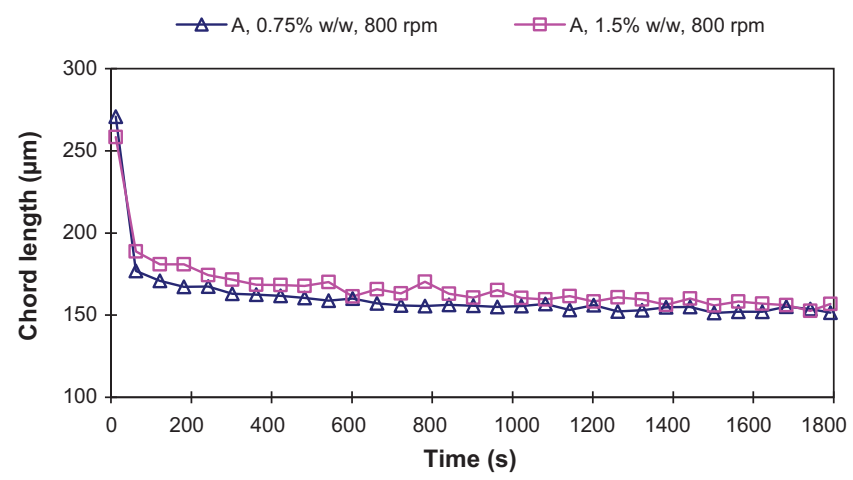

Figure A3. The effect of solid concentration on the chord length of powder A at $50{ }^{\circ} \mathrm{C}$.

$800 \mathrm{rpm}$ stirring rate. Duplicates were obtained for each measurement to get the average chord length. As shown in Figure A1, the reproducibility of FBRM is very good with a percentage error of $<5 \%$.

\subsection{The effect of external factors on FBRM's MPC chord length}

These tests were conducted to eliminate the possibility that external factors, such as stirring rate and powder concentration, had any effect on the FBRM particle size results.

The FBRM results of powder A tested at $50{ }^{\circ} \mathrm{C}$ with different stirring rates are as shown in Figure A2. It can be observed that the chord length for high stirring rate is smaller (more soluble) than that for low stirring rate. It can therefore be concluded that stirring rate has a substantial effect on the measured particle size. To investigate the effect of powder concentration, powder A was tested at different concentrations (1.5 and $0.75 \mathrm{wt} \%$ ), and the results are as shown in Figure A3. Negligible differences $(<5 \%)$ can be observed at different initial solid concentrations, indicating that the solid concentration has no observable effect on measured particle size.
Acknowledgements: The authors thank the Gardiner Foundation for Dairy Research and Dairy Innovation Australia Ltd. based in Melbourne, Australia, for their support of this project.

\section{REFERENCES}

[1] Anema S.G., Pinder D.N., Hunter R.J., Hemar Y., Effects of storage temperature on the solubility of milk protein concentrate (MPC85), Food Hydrocoll. 20 (2006) 386393.

[2] Barrett P., Glennon B., In-line FBRM monitoring of particle size in dilute agitated suspensions, Part. Part. Syst. Charact. 16 (1999) 207-211.

[3] Carr A., Bhaskar G., Ram S., Monovalent salt enhances solubility of milk protein concentrate, European Patent EP1553843, 2007.

[4] Castro-Morel M.D., Harper W.J., Basic functionality of commercial milk protein concentrates, Milchwissenschaft 57 (2002) 367-370.

[5] Chen X.D., Lloyd R.J., Some aspects of measuring the size and rate of dispersion of milk powder agglomerates using the Malvern Particle Sizer 2600c, J. Dairy Sci. 61 (1994) 201-208.

[6] Fang Y., Selomulya C., Chen X.D., On measurement of food powder reconstitution properties, Dry. Technol. 26 (2008) 3-14. 
[7] Gaiani C., Banon S., Scher J., Schuck P., Hardy J., Use of a turbidity sensor to characterize micellar casein powder rehydration: Influence of some technological effects, J. Dairy Sci. 88 (2005) 2700-2706.

[8] Gaiani C., Scher J., Schuck P., Desobry S., Banon S., Use of a turbidity sensor to determine dairy powder rehydration properties, Powder Technol. 190 (2009) 2-5.

[9] Gaiani C., Scher J., Schuck P., Hardy J., Desobry S., Banon S., The dissolution behaviour of native phosphocaseinate as a function of concentration and temperature using a rheological approach, Int. Dairy J. 16 (2006) 1427-1434.

[10] Gaiani C., Schuck P., Scher J., Desobry S., Banon S., Dairy powder rehydration: influence of protein state, incorporation mode, and agglomeration, J. Dairy Sci. 90 (2007) 570-581.

[11] Havea P., Protein interactions in milk protein concentrate powders, Int. Dairy J. 16 (2006) 415-422.

[12] Heath A.R., Fawell P.D., Bahri P.A., Swift J.D., Estimating average particle size by focused beam reflectance measurement (FBRM), Part. Part. Syst. Charact. 19 (2002) 84-95.

[13] Hu X., Cunningham J.C., Winstead D., Study growth kinetics in fluidized bed granulation with at-line FBRM, Int. J. Pharm. 347 (2008) 54-61.

[14] Kempkes M., Eggers J., Mazzotti M., Measurement of particle size and shape by FBRM and in situ microscopy, Chem. Eng. Sci. 63 (2008) 4656-4675.

[15] Kher A., Udabage P., McKinnon I., McNaughton D., Augustin M.A., FTIR investigation of spray-dried milk protein concentrate powders, Vib. Spectrosc. 44 (2007) 375-381.

[16] Kougoulos E., Jones A.G., Wood-Kaczmar M.W., Modelling particle disruption of an organic fine chemical compound using Lasentec focussed beam reflectance monitoring (FBRM) in agitated suspensions, Powder Technol. 155 (2005) 153-158.

[17] Kovalsky P., Bushell G., In situ measurement of fractal dimension using focussed beam reflectance measurement, Chem. Eng. J. 111 (2005) 181-188.

[18] Kwak B.-M., Lee J.E., Ahn J.-H., Jeon T.-H., Laser diffraction particle sizing by wet dispersion method for spray-dried infant formula, J. Food Eng. 92 (2009) 324-330.

[19] Mimouni A., Deeth H.C., Whittaker A.K., Gidley M.J., Bhandari B.R., Rehydration process of milk protein concentrate powder monitored by static light scattering, Food Hydrocoll. 23 (2009) 1958-1965.

[20] Mistry V.V., Hassan H.N., Delactosed, high milk protein powder. 2. Physical and functional properties, J. Dairy Sci. 74 (1991) 3716-3723.

[21] Niro, Insolubility Index, Niro Method, A 3 a, in: Niro Analytical Methods, September 2006, http://www.niro.com/niro/cmsdoc.nsf/ WebDoc/ndkw74jjk8.

[22] Yu W., Erickson K., Chord length characterization using focused beam reflectance measurement probe - methodologies and pitfalls, Powder Technol. 185 (2008) 24-30. 